Research Article

\title{
Adsorption of Azo Dye Acid Red 73 onto Rice Wine Lees: Adsorption Kinetics and Isotherms
}

\author{
Qian Wang, Liping Liang $(\mathbb{D}$, Fenfen Xi, Gangliang Tian, Qiaole Mao, and Xu Meng $\mathbb{D}$ \\ School of Civil Engineering, College of Life Science, College of Textile and Garment, Shaoxing University, Shaoxing 312000, China \\ Correspondence should be addressed to Liping Liang; liangliping0702@163.com and Xu Meng; mengxu0@163.com
}

Received 8 August 2019; Revised 24 November 2019; Accepted 10 January 2020; Published 26 February 2020

Academic Editor: Alain Portavoce

Copyright (c) 2020 Qian Wang et al. This is an open access article distributed under the Creative Commons Attribution License, which permits unrestricted use, distribution, and reproduction in any medium, provided the original work is properly cited.

\begin{abstract}
The adsorption properties of rice wine lees for acid red 73 in aqueous solution were studied in order to explore the recyclability of rice wine lees and to solve the pollution of dye-contaminated wastewater. Hence, the azo dye acid red 73 was selected as the model pollutant. Effects of parameters including $\mathrm{pH}$, rice wine lees dosage, and initial concentration of acid red 73 on the adsorption activity were investigated to determine the optimal conditions for removal of acid red 73. The experimental results showed that acid red 73 removal by rice wine lees decreased with increasing $\mathrm{pH}$ and initial concentration of acid red 73 and increased with increasing rice wine lees dosage. The adsorption reaction was consistent with pseudo-first-order kinetic models, and the adsorption process was physisorption. The adsorption isotherm could be described well with the Freundlich equation, and the maximum adsorption capacity was $18.74 \mathrm{mg} \cdot \mathrm{g}^{-1}$.
\end{abstract}

\section{Introduction}

At present, water pollution control is one of the main pollution controls. With the continuous development of light industry, dye wastewater has gradually become one of the important components of sewage. Dyes are widely used in textile, leather, cosmetics, paper, printing, plastics, medicine, food, and other industries, for coloring its products. Currently, more than 9000 kinds of dyes are included in the color index of various chemical application categories [1]. Dyes are usually more difficult to remove than soluble colorless organics. The synthetic sources are mainly complex aromatic molecular structures. The structure of this structure is often designed to prevent fading due to exposure to sweat, soap, water, light, or oxidants, making dye molecules more stable and less prone to degradation [2]. It is well known that many dyes are made from known carcinogens, and the color in the dye is a major component of biochemical oxygen demand (BOD) [3]. Acid red 73 (AR 73) is a very common azo dye, and its toxicity is greater than that of other dyes, such as acid red 88 , acid red 18 , acid orange 7 , and acid red 10 [4]. Residues in water can affect the health of organisms and humans. Long-term accumulation in the human body can cause bladder cancer or spleen tumors [5]. Therefore, it must be decolorized when discharging into rivers.
Generally, methods for treating dyes mainly include physical, chemical, and biological treatment methods. Among them, adsorption [6], coagulation [7], ultrafiltration [8], electrochemical [9], photocatalytic oxidation [10], and biodegradation method [11] are widely used. At the same time, the combination of coagulation, electrochemical oxidation, activated sludge, and other methods has also been proved to be feasible [12]. Among these methods, adsorption is considered to be a relatively effective method for removing dyes and controlling BOD. Since activated carbon has a good effect on the removal of dyes, it is currently the most commonly used dye removal adsorbent. However, the cost of activated carbon is high and regeneration is difficult, thus limiting the use to some extent. In view of the current status of adsorbents, it is still quite necessary to find cheap adsorbents. Some researchers have successfully degraded some dye wastewater by using agricultural waste such as peanut shell [13], straw [14], rice husk [15], and orange peel [16]. And Bhatnagar et al. found that the carbonaceous adsorbent prepared by the fertilizer plant has a good potential for dye removal [17]. It can be seen that some agricultural waste or industrial waste plays a more or less role in the removal of dyes, so the utilization of waste is crucial. If these wastes can be used, it not only solves the problem of dye wastewater 
treatment, but also solves the disposal problem of these wastes.

Biomass waste is rich in source and low in price and has a wide application prospect in the treatment of dye wastewater $[18,19]$. As one of the three brewed wines, the output of rice wine has increased year by year. In 2010, the output of the rice wine industry reached $1,341,400 \mathrm{~m}^{3}$. As a by-product of the production process of rice wine, the rice wine lees have a slag rate of $20-30 \%$, and the quantity is considerable. At present, rice wine lees are mainly used directly as feed, and the utilization rate is low, resulting in a large amount of rice wine lees. In the long run, it will pollute the environment. Since the main component of the rice wine lees is cellulose, its surface contains reactive groups such as hydroxyl groups and carboxyl groups [20]. So it is a renewable resource with great development potential. And Peng et al. successfully adsorbed reactive brilliant red and methylene blue by using rice wine lees [21]. Besides this, Xiaolian et al. used white distiller's grains to adsorb Congo red and malachite green [22]. It can be seen that the rice wine lees may be a good adsorbent.

In this study, rice wine lees were used as the adsorbent, and the acid red 73 dye wastewater was used as the model pollutant. The comprehensive effects of the $\mathrm{pH}$ of the solution, the dosage of the adsorbent, and the initial concentration of the dye on the adsorption of acid red 73 by rice wine lees were investigated. Adsorption isotherms and adsorption kinetics were fitted by experiment data to explore the adsorption mechanism.

\section{Materials and Methods}

2.1. Materials. Acid Red 73 purchased from Shandong Longsheng Chemical Co. Ltd (Shandong, China) was of analytical grade. The molecular structures were shown below. Other chemicals used in this study were obtained from Shanghai Qiangshun Chemical Reagent Company (Shanghai, China).

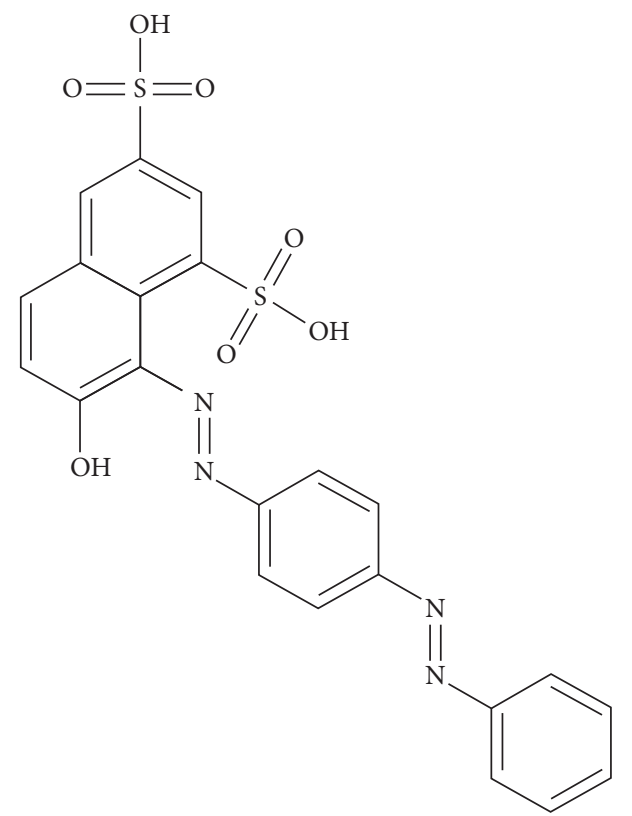

The rice wine lees were obtained from a Huangjiu factory in Shaoxing, and they were washed repeatedly with distilled water, after the rinsing, the rice wine lees were filtered and dried in an oven, and they were crushed and used for standby after being completely dried. The original rice wine lees were characterized by SEM, and Figure 1 shows the morphology images of the rice wine lees, and it had a complex net structure with pores, channels, and fibrous form which might be easy for adsorption.

2.2. Adsorption Experiments. Firstly, $0.500 \mathrm{~g}$ acid red 73 was accurately obtained and dissolved in a $500 \mathrm{~mL}$ volumetric flask with distilled water to configure a standard mother liquor with a concentration of $1 \mathrm{~g} \cdot \mathrm{L}^{-1}$ and diluted to the corresponding concentration according to the proportion used during the experiment. A certain amount of adsorbent was weighed into $500 \mathrm{~mL}$ of a certain concentration of acid red 73 containing solution, and $\mathrm{pH}$ was adjusted to the specified value, and then the solution was placed in a constant temperature shaking water bath and stirred with a stirrer rotating at $380 \mathrm{r} / \mathrm{min}$. The sample was filtrated through a $0.45 \mu \mathrm{m}$ membrane at a specific time, and then the concentration of residual acid red 73 in the solution was measured by a UV-visible spectrophotometer at a wavelength of $509 \mathrm{~nm}$.

2.3. Analytical Methods. A standard curve of absorbanceacid red 73 concentration was plotted based on the measured absorbance of acid red 73, and the equation was obtained as follows: $y=0.0219 x-0.0067, R^{2}=0.9991$. Due to the high corresponding correlation coefficients $\left(R^{2}\right)$ of 0.9991 , there was a good linear relationship between absorbance and concentration, which indicated that the equilibrium concentration of acid red 73 was more accurate. And then the amount of adsorption could be calculated by the following equation:

$$
q_{e}=\frac{\left(C_{0}-C_{e}\right) V}{W},
$$

where $q_{e}$ is the equilibrium concentration of acid red 73 (mg. $\left.\mathrm{g}^{-1}\right) ; C_{0}$ and $C_{e}$ are the initial and equilibrium concentrations of acid red $73\left(\mathrm{mg} \cdot \mathrm{L}^{-1}\right)$, respectively. $V$ is the volume of MG solution (L) and $W$ is the weight of used rice wine lees $(\mathrm{g})$.

\section{Results and Discussion}

3.1. Effect of Contact Time on Adsorption of Acid Red 73 by Rice Wine Lees. The effect of contact time on the adsorption of acid red 73 by rice wine lees was explored in the experiment, as shown in Figure 2. The initial concentration of the acid red 73 solution was $10 \mathrm{mg} \cdot \mathrm{L}^{-1}$, the $\mathrm{pH}$ of the solution was adjusted to 5 , the temperature was $298 \mathrm{~K}$, and the rice wine lees dosage was $10 \mathrm{~g} \cdot \mathrm{L}^{-1}$. From the figure, it could be concluded that during the $0-120$ min period, the adsorption amount increased rapidly. Within $120-180 \mathrm{~min}$, the adsorption 


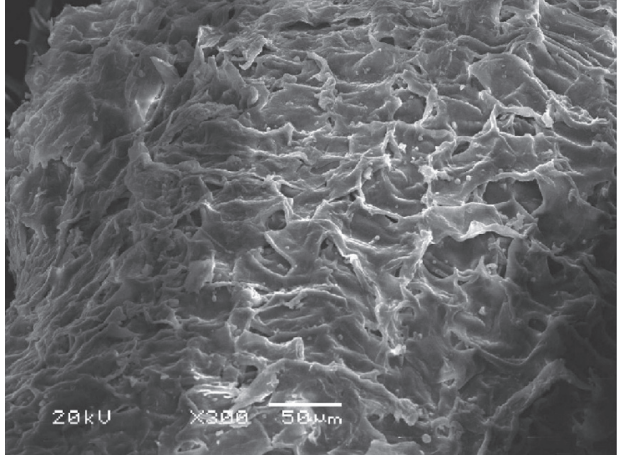

FIGURE 1: SEM characterization of original rice wine lees.

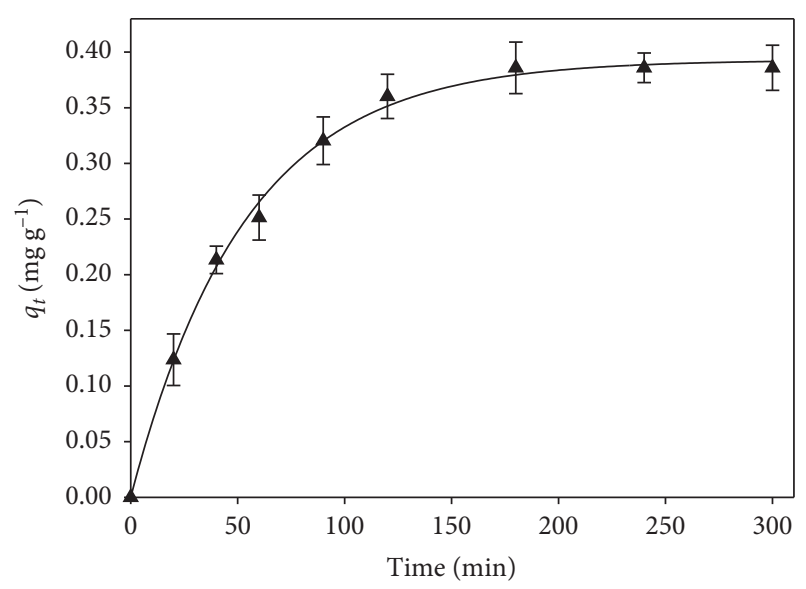

A $10 \mathrm{~g} / \mathrm{L}$

Figure 2: Adsorption of acid red 73 on rice wine lees as a function of contact time.

amount increased slowly. After that, the adsorption gradually became equilibrium, which may be due to the gradual saturation of the surface active sites of the adsorbents with the increase of reaction time. Therefore, the adsorption equilibrium time was $180 \mathrm{~min}$.

3.2. Effect of Initial pH on Adsorption of Acid Red 73 by Rice Wine Lees. The effect of initial $\mathrm{pH}$ on the removal rate of acid red 73 by rice wine lees with the same reaction conditions as above is shown in Figure 3. As the $\mathrm{pH}$ value increased, the acid red 73 removal rate decreased. When the $\mathrm{pH}$ was 3.00, the removal rate of acid red 73 was $96.51 \%$ after 20 minutes of reaction. As the $\mathrm{pH}$ reached $5.00,7.00$, and 9.00 , the removal rate of acid red 73 decreased to $90.81 \%$, $84.50 \%$, and $81.66 \%$ after $180 \mathrm{~min}$ of reaction, respectively. It could be seen that the $\mathrm{pH}$ of the solution has a certain influence on the adsorption of acid red 73 by rice wine lees, and lower $\mathrm{pH}$ was beneficial to the adsorption of acid red 73 . Kyzas et al. [23] also found a similar phenomenon in the experiment of removing dyes from untreated coffee grounds. This is due to the fact that, in strong acid environment, the positively charged rice wine lees were easy to adsorb the negatively charged acid red 73 molecules. As the $\mathrm{pH}$

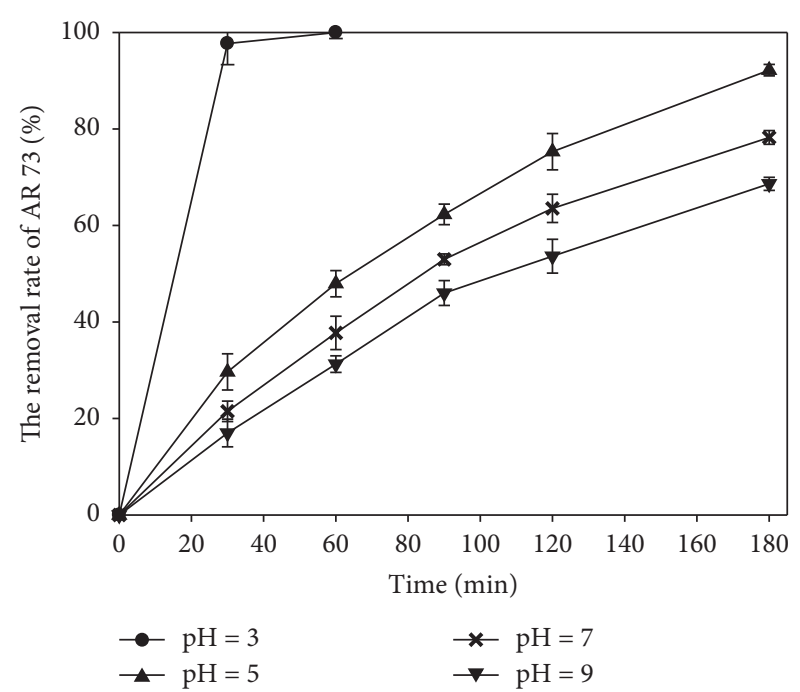

Figure 3: Effect of initial $\mathrm{pH}$ on the adsorption of acid red 73 by rice wine lees.

increased, the hydroxide in the solution increased and competed with dye molecules for the adsorption sites of the rice wine lees, resulting in the decrease of adsorption efficiency [21].

3.3. Effect of Rice Wine Lees Dosage on Acid Red 73 Adsorption. In the case of the initial dye concentration of $10 \mathrm{mg} \cdot \mathrm{L}^{-1}$ and the solution $\mathrm{pH}$ of 5 , four different rice wine lees dosages were selected to study the removal effect of dosage on acid red 73. And the results are shown in Figure 4. The removal efficiency of acid red 73 increased as the amount of rice wine lees increases. When the dosage of rice wine lees was $10 \mathrm{~g} \cdot \mathrm{L}^{-1}$ and $13 \mathrm{~g} \cdot \mathrm{L}^{-1}$, the removal rate of acid red 73 was $80.6 \%$ and $88.99 \%$ at $180 \mathrm{~min}$, respectively. As the amount of adsorbent added increased to $16 \mathrm{~g} \cdot \mathrm{L}^{-1}$ and $18 \mathrm{~g} \cdot \mathrm{L}^{-1}$, the removal rate of acid red 73 increased to $93.9 \%$ and $94.47 \%$. It could be seen that increasing the dosage of rice wine lees could increase the removal efficiency of acid red 73. This is because the adsorption of dyes occurs on the surface of adsorbent, and more rice wine lees provide more surface sites, thus accelerating the adsorption reaction.

3.4. Effect of Different Initial Concentrations on Adsorption of Acid Red 73 by Rice Wine Lees. In the same condition of $\mathrm{pH}$ value and the dosage of the adsorbent $\left(\mathrm{pH}=5\right.$ and $\left.10 \mathrm{~g} \cdot \mathrm{L}^{-1}\right)$, the adsorption of acid red 73 by rice wine lees at initial concentrations of $10,20,40,60$, and $80 \mathrm{mg} \cdot \mathrm{L}^{-1}$ was examined and the results are shown in Figure 5. The removal efficiency of acid red 73 gradually decreased with the increase of the initial concentration of acid red 73 . When the initial concentration of acid red 73 acid red was $10 \mathrm{mg} \cdot \mathrm{L}^{-1}$, after 20 hours of reaction, the removal rate of acid red 73 was $98.71 \%$. When the initial concentration of acid red 73 was increased to $20 \mathrm{mg} \cdot \mathrm{L}^{-1}, 40 \mathrm{mg} \cdot \mathrm{L}^{-1}$, and $60 \mathrm{mg} \cdot \mathrm{L}^{-1}$, the removal rate of acid red 73 was reduced to $98.53 \%, 98.36 \%$, and $98.25 \%$. As the initial concentration of acid red 73 was increased to $80 \mathrm{mg} \cdot \mathrm{L}^{-1}$, the removal rate of acid red 73 was 


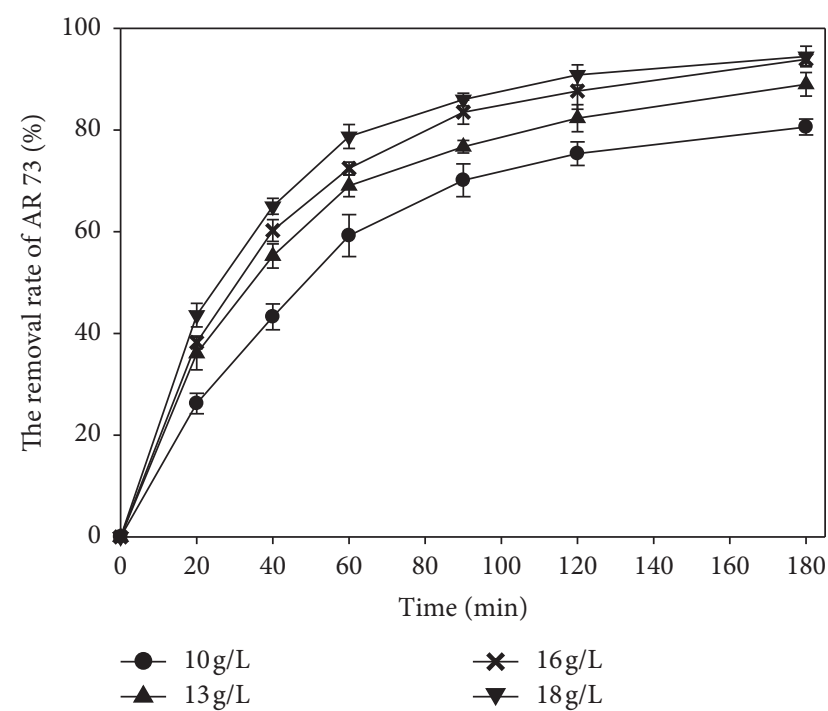

FIgURE 4: Effect of dosage of rice wine lees on removal of acid red 73.

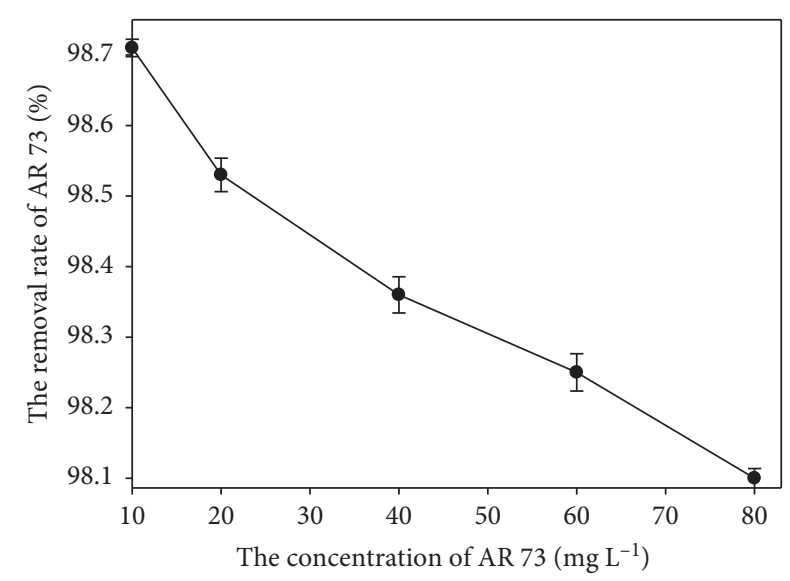

Figure 5: Removal rate of acid red 73 by rice wine lees after 20 hours.

only $98.10 \%$. The phenomenon that the concentration of acid red 73 increases and the removal rate decreases was mainly due to the fact that the adsorption sites of the adsorbent were gradually occupied [24].

3.5. Adsorption Isotherms. The adsorption isotherm refers to the relationship between the concentrations of the solute molecules at the two-phase interface when the adsorption process at the two-phase interface reaches equilibrium. The concentration relationship of the separated substance in the liquid phase and the solid phase at a certain temperature can be expressed by an adsorption equation. And the relationship between the adsorbent and the adsorbate can be inferred from the graph. In order to understand the adsorption effect of this adsorbent and the maximum adsorption amount, it is necessary to establish a balance curve and select the most suitable curve. Before establishing the isotherm, we first need to determine the time to reach the adsorption equilibrium. The experimental results showed that the adsorption of acid red 73 on the rice wine lees was completed within 180 minutes. Therefore, a contact time of $180 \mathrm{~min}$ was selected for all adsorption isotherms.

Langmuir equation is one of the commonly used adsorption isotherm equations, which assumes that the surface properties of the adsorbents are uniform and the adsorption behavior is monolayer adsorption on the solid surface. When the adsorption reaches equilibrium, the adsorption rate is equal to the desorption rate. Langmuir adsorption isotherm can be expressed by the following equation:

$$
\frac{q_{e}}{C_{e}}=\frac{C_{e}}{q_{m}}+\frac{1}{k_{L} q_{m}},
$$

where $q_{e}$ is the adsorption capacity of acid red 73 at equilibrium $\left(\mathrm{mg} \cdot \mathrm{L}^{-1}\right), C_{e}$ is the dye concentration at equilibrium $\left(\mathrm{mg} \cdot \mathrm{L}^{-1}\right), q_{m}$ is the saturated adsorption capacity $\left(\mathrm{mg} \cdot \mathrm{L}^{-1}\right)$, and $k_{L}$ is the equilibrium constant of Langmuir adsorption isotherm.

Freundlich isotherm equation describes the actual adsorption, which is an empirical formula, which is considered to be reversible and is not strictly the adsorption of the monomolecular layer. And Freundlich isotherm is represented by the following equation:

$$
\operatorname{Ln} q_{e}=\operatorname{Ln} K_{F}+\frac{1}{n} \operatorname{Ln} C_{e},
$$

where $q_{e}$ is the adsorption amount of the dye in equilibrium (mg. $\left.\mathrm{g}^{-1}\right), C_{e}$ is the concentration of dye at equilibrium (mg. $\left.\mathrm{L}^{-1}\right)$, and $K_{F}$ is the Freundlich constant.

Temkin considers the effects of some indirect adsorbate/ sorbent interactions and indicates that, due to these interactions, the heat of adsorption of all molecules in the layer decreases linearly with coverage. And Temkin isotherms can be represented by the following equation:

$$
q_{e}=\frac{\mathrm{RT}}{b_{T}} \mathrm{Ln} \quad A_{T}+\left(\frac{\mathrm{RT}}{b_{T}}\right) \mathrm{LnC}_{e},
$$

where $q_{e}$ is the amount of solute adsorbed per unit weight of adsorbent $\left(\mathrm{mg} \cdot \mathrm{g}^{-1}\right)$ and $C_{e}$ is the equilibrium concentration of acid red 73. And $R, A, T$, and $b$ are Temkin constants.

The linear regression method was used to fit the experimental data through three adsorption isotherms. The linear correlation coefficient and the model constants are shown in Table 1.

As shown in Table $1, R^{2}$ of the Freundlich model and $R^{2}$ of the Langmuir model were extremely high and obviously larger than $R^{2}$ of the Temkin model; therefore, both Freundlich and Langmuir could explain the adsorption behavior of acid red 73 on rice wine lees. Compared with the $R^{2}$ of the Freundlich model, it was larger than that of the Langmuir model; therefore Freundlich adsorption isotherm was more suitable for describing the adsorption of dye on rice wine lees. $1 / n$ also showed that acid red 73 was favorable for adsorption on rice wine lees. The isotherm diagram of acid red 73 adsorbed on rice wine lees is shown in Figure 6. The Freundlich equation obtained by fitting was $y=$ $0.8414 x+2.426\left(R^{2}=0.9998\right)$, and the maximum adsorption 
TABLE 1: The isotherm adsorption constant and correlation of Langmuir, Freundlich, and Temkin adsorption of acid red 73 by rice wine lees.

\begin{tabular}{lcccccccc}
\hline & Langmuir parameters & \multicolumn{3}{c}{ Freundlich parameters } & \multicolumn{3}{c}{ Temkin parameters } \\
$R^{2}$ & $Q_{m}\left(\mathrm{mg} \cdot \mathrm{g}^{-1}\right)$ & $k\left({\left.\mathrm{~L} \cdot \mathrm{g}^{-1}\right)}^{18.74}\right.$ & 1.436 & $R^{2}$ & $K\left(\mathrm{mg}^{1-n} \cdot \mathrm{L}^{n} \cdot \mathrm{g}^{-1}\right)$ & $n$ & $R^{2}$ & $K\left(\mathrm{~L} \cdot \mathrm{g}^{-1}\right)$ \\
\hline 0.9975 & 18.9998 & 11.313 & 1.188 & 0.9396 & 427.990 & 0.165 \\
\hline
\end{tabular}

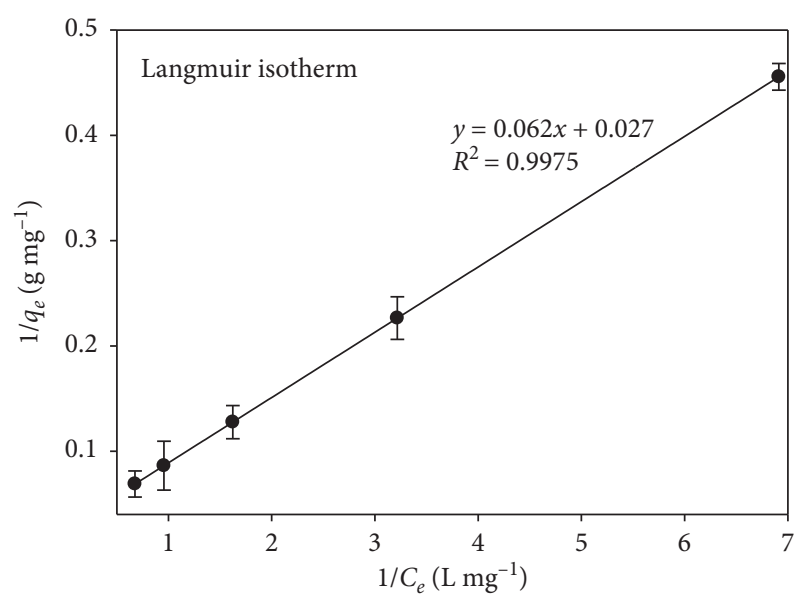

(a)

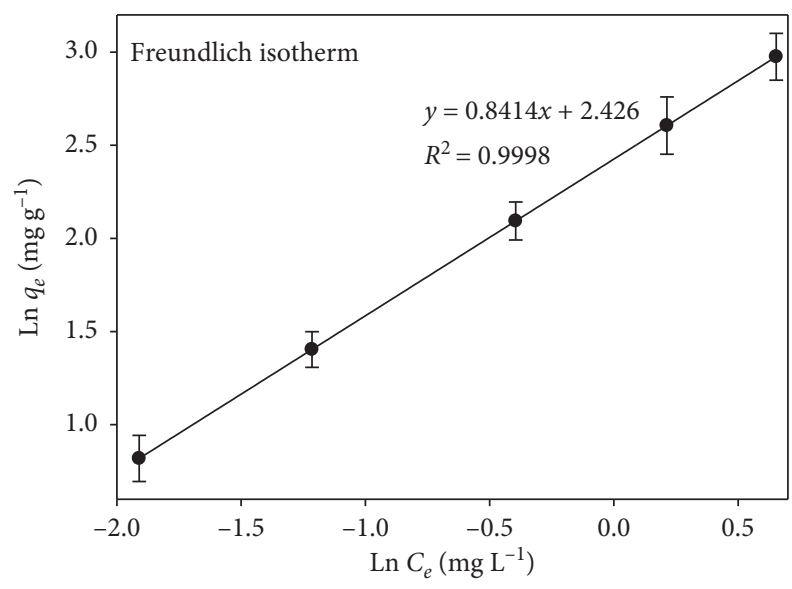

(b)

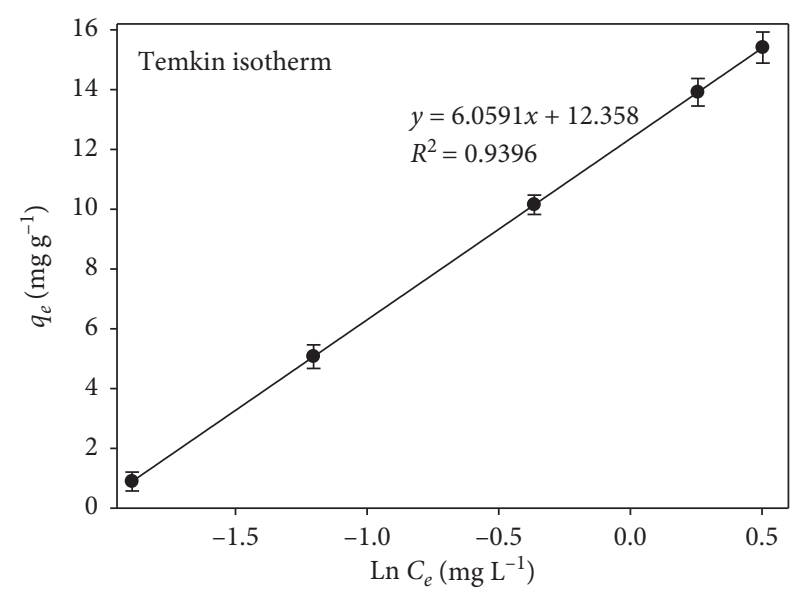

(c)

FIgURE 6: The adsorption isotherm plots of acid red 73 adsorbed on rice wine lees.

capacity of the rice wine lees was $18.74 \mathrm{mg} \cdot \mathrm{g}^{-1}$ calculated by the Langmuir model. In addition, we compared the adsorption capacity of other materials to acid red 73 and found that rice wine lees have a good removal effect. The specific information is shown in Table 2.

3.6. Adsorption Kinetics. In order to investigate the adsorption process of acid red 73 on rice wine lees, the pseudofirst-order model, the pseudo-second-order kinetic model, and the intraparticle diffusion model were used, which were represented by the following equations, respectively:

$$
\begin{aligned}
\operatorname{Ln}\left(q_{e}-q_{t}\right) & =\operatorname{Ln} q_{e}-k_{1} t \\
\frac{t}{q_{t}} & =\frac{1}{k_{2} q_{e}^{2}}+\frac{t}{q_{e}},
\end{aligned}
$$

$$
q_{t}=k_{i d} t^{1 / 2}+C
$$

where $q_{e}$ and $q_{t}\left(\mathrm{mg} \cdot \mathrm{g}^{-1}\right)$ are the amounts of AR 73 at equilibrium and at any time $t$. And $k_{1}$ and $k_{2}$ are the rate constants of pseudo-first-order and pseudo-second-order adsorption. $k_{i d}$ is the rate constant of the intraparticle diffusion model and $C$ is truncation. The kinetic parameters were obtained by linear regression method. And the results are shown in Table 3 and Figure 7, respectively. It was found that the correlation coefficient of the pseudo-first-order model was higher than that of the pseudo-second-order model and the intraparticle diffusion model, indicating that the pseudo-first-order kinetic model would better describe the adsorption process of acid red 73 on rice wine lees. This illustrated that the process was physical adsorption. The reaction rate of the adsorption of acid red 73 by rice wine lees 
TABLE 2: Adsorption capacities of various adsorbents for acid red 73.

\begin{tabular}{|c|c|c|c|}
\hline Adsorbent $\left(\mathrm{g} \cdot \mathrm{L}^{-1}\right)$ & Major reaction conditions & $\begin{array}{c}Q_{m} \\
\left(\mathrm{mg} \cdot \mathrm{g}^{-1}\right)\end{array}$ & $\begin{array}{c}\text { Source of } \\
\text { information }\end{array}$ \\
\hline Rice wine lees & $\begin{aligned} {\left[\text { dye }_{0}=10 \mathrm{mg} \cdot \mathrm{L}^{-1},[\text { adsorbent }]_{0}\right.} & =10 \mathrm{~g} \cdot \mathrm{L}^{-1}, T=298 \mathrm{~K}, \mathrm{pH}=5, \text { reaction } \\
\text { time } & =180 \mathrm{~min}\end{aligned}$ & 18.74 & $\begin{array}{l}\text { The data from this } \\
\text { paper }\end{array}$ \\
\hline Magnetic nano- $\mathrm{Fe}_{3} \mathrm{O}_{4}$ & 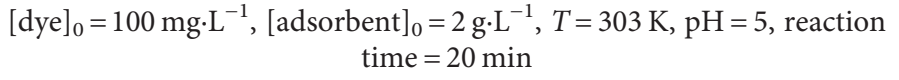 & 40.16 & [25] \\
\hline $\begin{array}{l}\text { Copper } \\
\text { diethyldithiocarbamate }\end{array}$ & {$[\text { dye }]_{0}=500 \mathrm{mg} \cdot \mathrm{L}^{-1},[\text { adsorbent }]_{0}=0.5 \mathrm{~g} \cdot \mathrm{L}^{-1}, T=302-304 \mathrm{~K}, \mathrm{pH}=7$,} & 42.9 & {$[26]$} \\
\hline $\begin{array}{l}\text { Copper } \\
\text { dimethyldithiocarbamate }\end{array}$ & reaction time $=180 \mathrm{~min}$ & 37.8 & {$[20]$} \\
\hline Chitosan & $\begin{array}{c}\left.[\text { dye }]_{0}=50 \mathrm{mg} \cdot \mathrm{L}^{-1}, \text { adsorbent }\right]_{0}=5 \mathrm{~g} \cdot \mathrm{L}^{-1}, T=298 \mathrm{~K}, \mathrm{pH}=7 \text {, reaction } \\
\text { time }=380 \mathrm{~min}\end{array}$ & 8.216 & [27] \\
\hline Nano- $\mathrm{Fe}_{3} \mathrm{O}_{4}$ & $\begin{aligned} {[\text { dye }]_{0}=75 \mathrm{mg} \cdot \mathrm{L}^{-1},[\text { adsorbent }]_{0} } & =2 \mathrm{~g} \cdot \mathrm{L}^{-1}, T=303 \mathrm{~K}, \mathrm{pH}=5, \text { reaction } \\
\text { time } & =30 \mathrm{~min}\end{aligned}$ & 12.312 & [28] \\
\hline Nano- $\mathrm{TiO}_{2}$ & $\begin{array}{c}{[\text { dye }]_{0}=1 \mathrm{~g} \cdot \mathrm{L}^{-1},[\text { adsorbent }]_{0}=8.2 \mathrm{~g} \cdot \mathrm{L}^{-1}, T=298 \mathrm{~K}, \mathrm{pH}=7 \text {, reaction }} \\
\text { time }=40 \mathrm{~min}\end{array}$ & 9.7166 & [29] \\
\hline
\end{tabular}

TABLE 3: Kinetic parameters for the adsorption of acid red 73 on the rice wine lees.

\begin{tabular}{lccccccr}
\hline \multirow{2}{*}{ Rice wine lees $\left(\mathrm{g} \cdot \mathrm{L}^{-1}\right)$} & \multirow{2}{*}{$q_{e}\left(\mathrm{mg} \cdot \mathrm{g}^{-1}\right)$} & \multicolumn{2}{c}{ Pseudo-first-order model } & \multicolumn{2}{c}{ Pseudo-second-order model } & \multicolumn{2}{c}{ Intraparticle diffusion model } \\
& & $R^{2}$ & $K_{1}\left(\mathrm{~g} \cdot \mathrm{mg}^{-1} \cdot \mathrm{min}^{-1}\right)$ & $R^{2}$ & $K_{2}\left(\mathrm{~g} \cdot \mathrm{mg}^{-1} \cdot \mathrm{min}^{-1}\right)$ & $R^{2}$ & $K_{\mathrm{id}}\left(\mathrm{g} \cdot \mathrm{mg}^{-1} \cdot \mathrm{min}^{-1}\right)$ \\
\hline 10 & 0.927 & 0.997 & -0.010 & 0.994 & 0.795 & 0.981 & 0.057 \\
13 & 1.096 & 0.984 & -0.019 & 0.940 & 1.018 & 0.888 \\
16 & 1.032 & 0.977 & -0.021 & 0.964 & 0.846 & 0.928 & 0.064 \\
18 & 1.068 & 0.997 & -0.027 & 0.971 & 1.041 & 0.920 & 0.083 \\
\hline
\end{tabular}

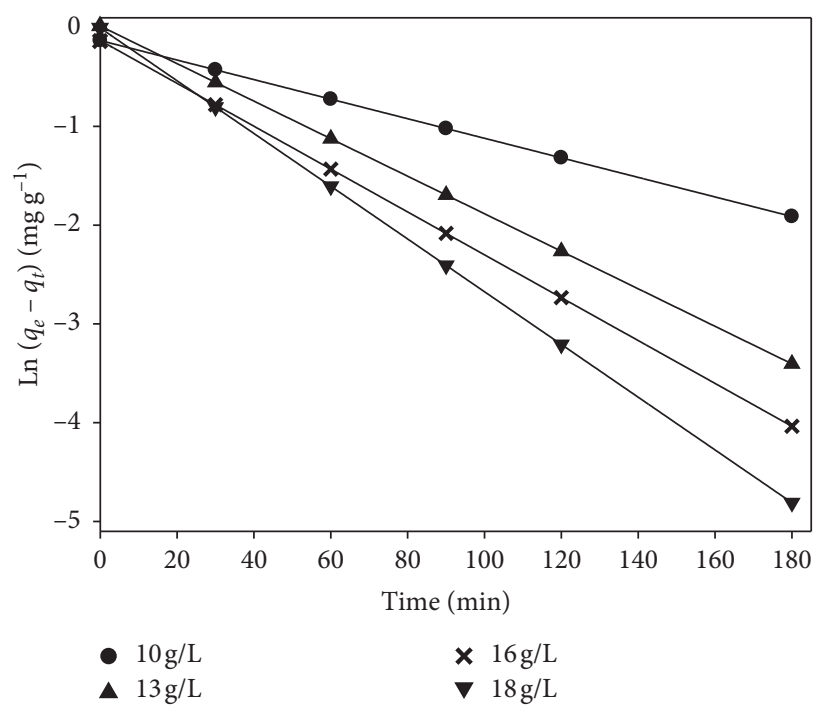

(a)

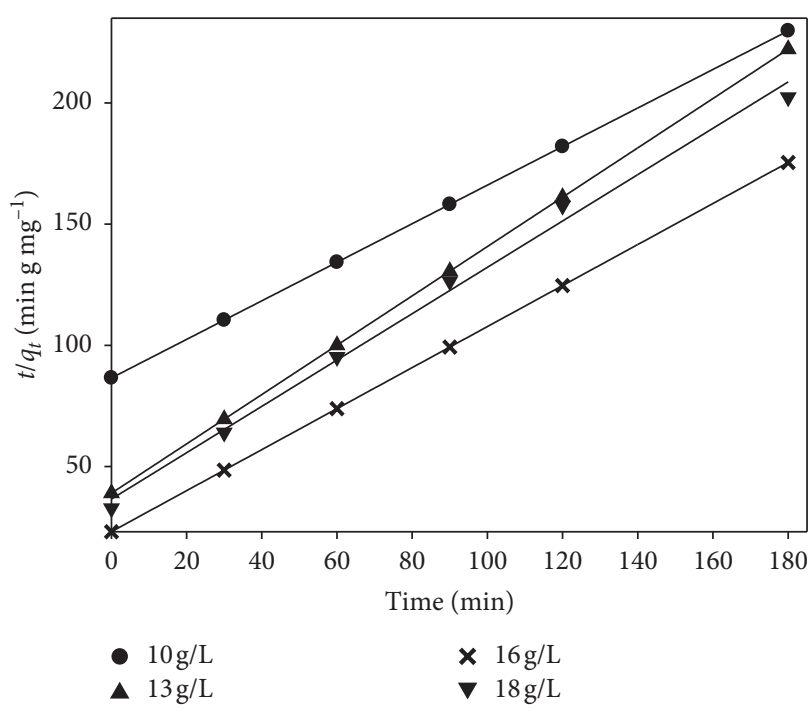

(b)

Figure 7: Continued. 


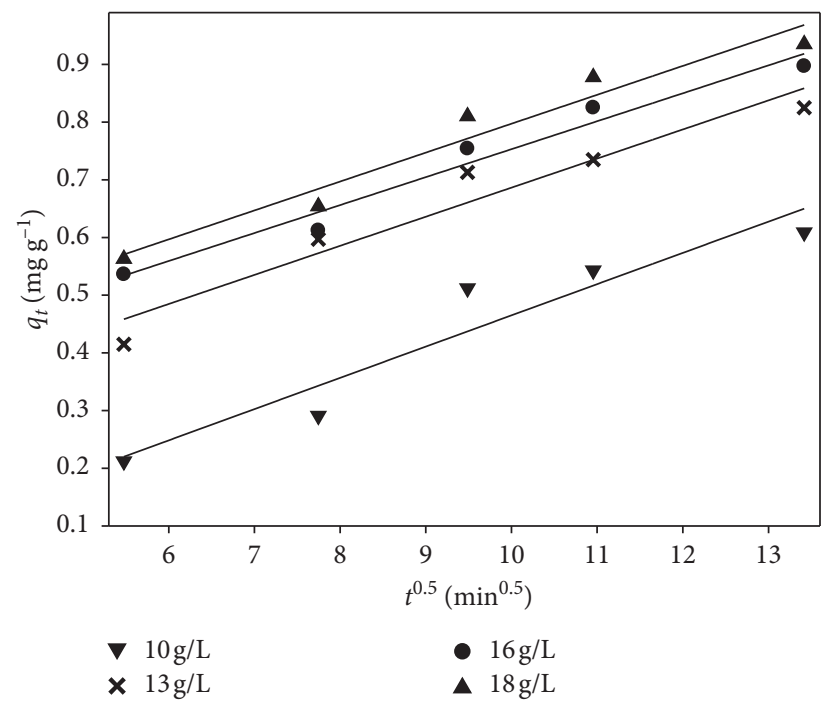

(c)

FIgURE 7: The adsorption kinetics plots for acid red 73 dye adsorption on rice wine lees.

was linear with the concentration of acid red 73. And the adsorption process involved transporting the adsorbate from a large amount of solution to the inner surface of the pore [30]. It was possible to control the transport of the dye from the solution into the pores of the adsorbent by rapid agitation in a batch experiment [15]. In addition, according to the pseudo-first-order kinetic fitting results, the calculated values of the adsorption capacity calculated from the slope and the intercept in the linear graph were $0.916,1.015,1.027$, and $1.043 \mathrm{mg} \cdot \mathrm{g}^{-1}$, respectively, which was similar to the $q_{e}$ obtained from the experiment in Table 3.

\section{Conclusion}

In this study, the model pollutants of azo dye acid red 73 were used to investigate the effects of $\mathrm{pH}$, initial concentration of acid red 73, and dosage of rice wine lees on adsorption performance. The experimental results showed that the effect of solution $\mathrm{pH}$ on adsorption performance was significant, and the adsorption performance increased with the decrease of $\mathrm{pH}$ and decreased with the increase of initial concentration of dye. At the same time, the greater the amount of rice wine lees added, the more obvious the removal effect. By fitting the data, it was found that the adsorption reaction of rice wine lees to acid red 73 was consistent with the Freundlich isotherm adsorption model. The maximum adsorption capacity was $18.74 \mathrm{mg} \cdot \mathrm{g}^{-1}$. The adsorption process accorded with pseudo-first-order model kinetics, and the adsorption process was physisorption.

\section{Data Availability}

The data used to support the findings of this study are available from the corresponding author upon request.

\section{Conflicts of Interest}

The authors declare that there are no conflicts of interest regarding the publication of this paper.

\section{Acknowledgments}

The authors gratefully acknowledge the financial support of the National Natural Science Foundation of China (Grant no. 41807468), Zhejiang Provincial Natural Science Foundation of China (Grant no. LY18E080018), Shaoxing Public Welfare Project (Grant no. 2017B70042), National Innovation and Entrepreneurship Training Program for College Students (Grant no. 201810349008), Zhejiang University Students' Science and Technology Innovation Program (Young Talents Program) (Grant no. 2018R432004), and State Key Laboratory of Pollution Control and Resource Reuse Foundation (Grant no. PCRRF18021).

\section{References}

[1] V. K. Gag, R. Kumar, and R. Gupta, "Removal of malachite green dye from aqueous solution by adsorption using agroindustry waste: a case study of prosopis cineraria," Dyes and Pigments, vol. 62, no. 1, pp. 1-10, 2004.

[2] K. S. Low, C. K. Lee, and W. H. Koo, "Sorption of acid dyes by chemically modified peanut hulls," Bulletin of Environmental Contamination \& Toxicology, vol. 62, no. 4, pp. 428-433, 1999.

[3] I. M. Banat, P. Nigam, D. Singh, and R. Marchant, "Microbial decolorization of textile-dye-containing effluents: a review," Bioresource Technology, vol. 58, no. 3, pp. 217-227, 1996.

[4] M. Muthukumar, D. Sargunamani, M. Senthilkumar, and N. Selvakumar, "Studies on decolouration, toxicity and the possibility for recycling of acid dye effluents using ozone treatment," Dyes \& Pigments, vol. 64, no. 1, pp. 39-44, 2005.

[5] A. B. dos Santos, I. A. E. Bisschops, F. J. Cervantes, and J. B. V. Lier, "The transformation and toxicity of 
anthraquinone dyes during thermophilic $\left(55^{\circ} \mathrm{C}\right)$ and mesophilic $\left(30^{\circ} \mathrm{C}\right)$ anaerobic treatments," Journal of Biotechnology, vol. 115, no. 4, pp. 345-353, 2005.

[6] G. Mckay, H. S. Blair, and J. R. Gardner, "Adsorption of dyes on chitin. I. Equilibrium studies," Journal of Applied Polymer Science, vol. 27, no. 8, pp. 3043-3057, 2010.

[7] O. S. Amuda and I. A. Amoo, "Coagulation/flocculation process and sludge conditioning in beverage industrial wastewater treatment," Journal of Hazardous Materials, vol. 141, no. 3, pp. 778-783, 2007.

[8] H. Lachheb, E. Puzenat, A. Houas et al., "Photocatalytic degradation of various types of dyes (alizarin s, crocein orange g, methyl red, congo red, methylene blue) in water by UVirradiated titania," Applied Catalysis B Environmental, vol. 39, no. 1, pp. 75-90, 2002.

[9] P. Kariyajjanavar, N. Jogttappa, and Y. A. Nayaka, "Studies on degradation of reactive textile dyes solution by electrochemical method," Journal of Hazardous Materials, vol. 190, no. 1-3, pp. 952-961, 2011.

[10] T. Wu, L. Tong, J. Zhao, H. Hidaka, and N. Serpone, "Tio ${ }^{-}$ assisted photodegradation of dyes. 9. photooxidation of a squarylium cyanine dye in aqueous dispersions under visible light irradiation," Environmental Science \& Technology, vol. 33, no. 9, pp. 1379-1387, 1999.

[11] J. Srinagar, T. Senthilvelan, and R. C. Panda, "Degradation of azo dyes by laccase: biological method to reduce pollution load in dye wastewater," Clean Technologies and Environmental Policy, vol. 17, no. 6, pp. 1443-1456, 2015.

[12] S. H. Lin and C. F. Peng, "Continuous treatment of textile wastewater by combined coagulation, electrochemical oxidation and activated sludge," Water Research, vol. 30, no. 3, pp. 587-592, 1996.

[13] J. Liu, Z. Wang, H. Li, C. Hu, P. Raymer, and Q. Huang, "Effect of solid state fermentation of peanut shell on its dye adsorption performance," Bioresource Technology, vol. 249, no. 4, pp. 307-314, 2018.

[14] W. Zhang, H. Yang, L. Dong et al., "Efficient removal of both cationic and anionic dyes from aqueous solutions using a novel amphoteric straw-based adsorbent," Carbohydrate Polymers, vol. 90, no. 2, pp. 887-893, 2012.

[15] P. K. Malik, "Use of activated carbons prepared from sawdust and rice-husk for adsorption of acid dyes: a case study of acid yellow 36," Dyes \& Pigments, vol. 56, no. 3, pp. 239-249, 2003.

[16] C. Namasivayam, N. Muniasamy, K. Gayatri, M. Rani, and K. Ranganathan, "Removal of dyes from aqueous solutions by cellulosic waste orange peel," Bioresource Technology, vol. 57, no. 1, pp. 37-43, 1996.

[17] A. Bhatnagar and A. K. Jain, "A comparative adsorption study with different industrial wastes as adsorbents for the removal of cationic dyes from water," Journal of Colloid and Interface Science, vol. 281, no. 1, pp. 49-55, 2005.

[18] A. Mahwish and B. H. Nawaz, "Removal of reactive blue 19 and reactive blue 49 textile dyes by citrus waste biomass from aqueous solution: equilibrium and kinetic study," The $\mathrm{Ca}$ nadian Journal of Chemical Engineering, vol. 90, no. 2, pp. 412-419, 2012.

[19] M. Kaya, "Evaluation of a novel woody waste obtained from tea tree sawdust as an adsorbent for dye removal," Wood Science and Technology, vol. 52, no. 1, pp. 245-260, 2018.

[20] J. Kang, Q. Guo, and Y. C. Shi, "Molecular and conformational properties of hemicellulose fiber gum from dried distillers grains with solubles," Food Hydrocolloids, vol. 80, pp. 53-59, 2018.
[21] P. Na, W. Kaifeng, T. Changqing, and L. Zhong, "Adsorption capability of rice wine lees to reactive brilliant red and methylene blue," Environmental Protection of Chemical Industry, vol. 31, no. 5, pp. 464-468, 2011.

[22] Z. Xiaolian, L. Zihui, Y. Xing, S. Yisheng, Z. Qingle, and Z. Liqing, "Adsorption mechanism of distillers' grain to conge red and malachite green," New Chemical Materials, vol. 44, no. 2, pp. 207-213, 2016.

[23] G. Z. Kyzas, N. K. Lazaridis, and A. C. Mitropoulos, "Removal of dyes from aqueous solutions with untreated coffee residues as potential low-cost adsorbents: equilibrium, reuse and thermodynamic approach," Chemical Engineering Journal, vol. 189-190, pp. 148-159, 2012.

[24] S. Chatterjee, S. Chatterjee, B. P. Chatterjee, A. R. Das, and A. K. Guha, "Adsorption of a model anionic dye, eosin Y, from aqueous solution by chitosan hydrobeads," Journal of Colloid and Interface Science, vol. 288, no. 1, pp. 30-35, 2005.

[25] X. Zengmeng, T. Bing, C. Xuan et al., "Adsorption mechanism of acid red 73 onto magnetic nanoparticles $\mathrm{Fe}_{3} \mathrm{O}_{4}$ from aqueous phase," Acta Scientiae Circumstantiae, vol. 34, no. 9, pp. 2246-2255, 2014.

[26] F. Fu, Y. Xiong, B. Xie, and R. Chen, "Adsorption of Acid Red 73 on copper dithiocarbamate precipitate-type solid wastes," Chemosphere, vol. 66, no. 1, 2006.

[27] W. Jia, C. Xiao-Ting, W. Hu et al., "Adsorption kinetics research on Chitosan powder Obrilliant crocein," Contemporary Chemical Research, no. 4, pp. 184-185, 2019.

[28] Z. Xiaoshan, F. Xianfeng, C. Qianyu et al., "Investigation of adsorption and desorption behaviors of nanoFe_3O_4 for acid red 73," Guangdong Chemical Industry, vol. 42, no. 304, pp. 11-13, 2015.

[29] W. Hu, D. Bao-Jia, C. Xiao-Ting et al., "Preparation of nanoTiO_2/chitosan hydrogel and its adsorption on acid red 73," Chemical Engineering Design Communications, vol. 44, no. 9, pp. 62-64, 2018.

[30] B. K. Singh and N. S. Rawat, "Comparative sorption kineticstudies of phenolic-compounds on fly-ash and impregnated fly-ash," Journal of Chemical Technology \& Biotechnology Biotechnology, vol. 61, no. 1, pp. 57-65, 2010. 